\title{
Possible mechanisms of the antimicrobial effects of polypeptide-enriched Gastrodia elata Blume extracts
}

\author{
FANGE KONG $^{1 *}$, XUEYING CAI $^{1 *}$, SIYU ZHAI $^{1}$, RUOCHEN WANG $^{1}$, \\ XIAOYI ZHENG ${ }^{2}$, YUE MA ${ }^{3}, \mathrm{HUI} \mathrm{BI}^{4}$ and DI WANG ${ }^{1}$ \\ ${ }^{1}$ School of Life Sciences, Jilin University, Changchun, Jilin 130012, P.R. China; ${ }^{2}$ Division of Nephrology, \\ Stanford University School of Medicine, Stanford, CA 94305, USA; ${ }^{3}$ Department of Radiology, \\ The First Hospital of Jilin University; ${ }^{4}$ Department of Anesthesiology, Hospital of \\ Stomatology, Jilin University, Changchun, Jilin 130021, P.R. China
}

Received March 20, 2019; Accepted August 5, 2019

DOI: $10.3892 / \mathrm{mmr} .2019 .10706$

\begin{abstract}
The present study aimed to evaluate the antimicrobial activity and the possible mechanisms of activity of polypeptide-enriched Gastrodia elata extracts (GEP) against the gram-negative bacteria Escherichia coli and Pseudomonas aeruginosa, the gram-positive bacterium Staphylococcus aureus and the fungus Candida albicans. The antimicrobial activity of GEP was first confirmed by determining the minimum inhibitory concentration by growth curve analysis. GEP was found to damage the cell wall and membrane of the microorganisms tested, as revealed by the morphological changes visible through scanning electron microscopy, and by the observed leakage of alkaline phosphatase and $\beta$-galactosidase from cells. GEP was demonstrated to perturb the metabolism of the microorganisms, especially the tricarboxylic acid cycle, as indicated by the reduced intracellular activity of succinate dehydrogenase, malate dehydrogenase and ATPases, including the $\mathrm{Na}^{+} / \mathrm{K}^{+}$-ATPase and the $\mathrm{Ca} 2^{+}$-ATPase. In addition, GEP caused the leakage of the genetic material of the bacteria and the fungus, as indicated by the increased $\mathrm{OD}_{260}$. The results of the present study indicated that GEP may exert its antimicrobial activity by damaging cell walls and membranes, causing the leakage of genetic material, and by perturbing cellular metabolism.
\end{abstract}

Correspondence to: Professor Di Wang, School of Life Sciences, Jilin University, 2699 Qianjin Street, Changchun, Jilin 130012, P.R. China

E-mail: jluwangdi@outlook.com

Dr Hui Bi, Department of Anesthesiology, Hospital of Stomatology, Jilin University, 1500 Qinghua Road, Changchun, Jilin 130021, P.R. China

E-mail: bihui0431@126.com

${ }^{*}$ Contributed equally

Key words: Gastrodia elata Blume, natural product, polypeptide, antimicrobial activities, energy metabolisms

\section{Introduction}

Fungal and bacterial infections cause serious problems in medicine, the environment and the food industry. Candida albicans causes vaginal candidiasis, which affects 75 million women every year (1). Staphylococcus aureus, the most common pathogen in human purulent infections, is responsible for food poisoning, osteomyelitis, and chronic and recurrent infections that are difficult to prevent using antibiotics (2). Antibiotic resistance in bacteria, such as $S$. aureus and Pseudomonas aeruginosa, is becoming increasingly prevalent and serious (3). Escherichia coli can cause gastrointestinal or urethral tract infections in humans and animals under certain conditions. A range of existing biocides, including antibiotics (4), metal particles (silver or tin), titanium oxide (5) and quaternary ammonium salts (6), have been banned owing to their toxicity (7). Researchers are therefore investigating natural broad-spectrum antibacterial agents that may be used to reduce the problem of drug resistance (8-10). Plant-derived compounds, including tannins, flavonoids, alkaloids and peptides have been reported to exhibit therapeutic action against bacterial infection (11-13), indicating their utility as antibacterial substances. Antibacterial drugs are classified according to four mechanism of action: i) interference with cell wall synthesis; ii) causing damage to the plasma membrane; iii) inhibiting bacterial protein synthesis; and iv) affecting nucleic acid metabolism.

The rhizome of the orchid Gastrodia elata Blume, has been used medicinally in Asian countries for $>2,000$ years $(14,15)$ owing to its various pharmacological actions, including anti-epilepsy (16), anti-convulsion (15), anti-inflammation $(17,18)$ and anti-tetanus $(16)$. Among its active ingredients, the polypeptides have received wide attention. G. elata protein extracts have been reported to have significant antifungal activity and antibacterial activity against gram-positive bacteria, and exhibits little hemolytic activity on rabbit red blood cells (19). In our previous study, the antimicrobial activities of polypeptide-enriched G. elata extracts (GEP) were demonstrated using the agar diffusion method (20) and its effects on C.albicans were confirmed in a mouse model of vulvovaginal candidiasis. However, the antimicrobial mechanism of action of GEP has, to the best of our knowledge, not yet been reported. 
The present study aimed to investigate the possible mechanism of GEP-mediated antimicrobial efficacy on C. albicans, E. coli, S. aureus and P. aeruginosa by determining its effect on cell walls, cell membranes and the levels of intracellular and extracellular proteins. Data from the present study suggested that the antimicrobial effects of GEP may be related to the modulation of membrane integrity and intracellular energy metabolism.

\section{Materials and methods}

Preparation of GEP and molar mass distribution analysis. In the Changbai Mountain region (Jilin, China), G. elata has been planted artificially, and is an economic species. In the present study, the cultured G. elata rhizomes were purchased from Taobao and stored at room temperature. The rhizomes of G. elata were crushed and extracted for $2 \mathrm{~h}$ in saline at $80^{\circ} \mathrm{C}$, the resulting solution was then filtered. Papain (Shanghai Yuanye Biological Technology Co., Ltd.) was added to the collected filtrate to give a final concentration of $0.32 \mathrm{~g} / \mathrm{liter}$. The resulting solution was heated at $60^{\circ} \mathrm{C}$ for $30 \mathrm{~min}$ (to trigger papain-mediated hydrolysis) and then heated in a water bath at $100^{\circ} \mathrm{C}$ for a further $40 \mathrm{~min}$ (to inactivate the papain). Subsequently, the solution was passed through a $10 \mathrm{kDa}$ ultrafiltration membrane (Sartocon 2 PES; Sartorius AG), and the resulting filtrate was concentrated by rotary evaporation at $60^{\circ} \mathrm{C}$ with a rotation speed of $10 \mathrm{rpm}$ until the extract was determined to have a concentration of $22.5 \mathrm{~g} / 1$ using the bicinchoninic acid (BCA) method.

The molar mass distribution of GEP was determined using gel permeation chromatography (Wyatt Technology) equipped with two serial OHpak polymer matrix phase columns (OHpak SB-806 and 803; 8.0x300 mm; Shodex). The samples were eluted using a $0.02 \%$ aqueous solution of $\mathrm{NaN} 3$, at a flow-rate of $1 \mathrm{ml} / \mathrm{min}$ at $40^{\circ} \mathrm{C}$. Calculations of the average molar masses [number average molar mass $(\mathrm{Mn})$, weight-average molar mass $(\mathrm{Mw}), \mathrm{z}$-average molar mass $(\mathrm{Mz})]$ and dispersity index $(\mathrm{Mw} / \mathrm{Mn})$ were calculated using Omi SEC v4.7 software (Malvern Panalytical).

Strains and culture condition. In total, four microbial strains, C. albicans (cat. no. ATCC 10231), E. coli (cat. no. 8099), $S$. aureus (cat. no. ATCC 6538) and P. aeruginosa (cat. no. ATCC 27853) were supplied by the Guangdong Microbial Culture Center. The bacterial strains were cultured in lysogeny broth $(10 \mathrm{~g} / 1$ peptone, $5 \mathrm{~g} / 1$ yeast extract and $10 \mathrm{~g} / 1 \mathrm{NaCl})$ at $37^{\circ} \mathrm{C}$ with shaking at $150 \mathrm{rpm}$ for $20 \mathrm{~h}$. C. albicans was cultured in Sabouraud Dextrose Broth (Qingdao Hope Bio-Technology Co., Ltd.) at $28^{\circ} \mathrm{C}$ with shaking at $150 \mathrm{rpm}$ for $20 \mathrm{~h}$.

Determination of the minimum inhibitory concentration (MIC). After culturing for $20 \mathrm{~h}$, suspensions with a final concentration of $1 \times 10^{6}$ colony-forming units $(\mathrm{CFU}) / \mathrm{ml}$ were collected. For each microbial strain, $100 \mu \mathrm{l}$ aliquots of prepared suspension were added to 96-well plates and $100 \mu \mathrm{l}$ aliquots containing different concentrations of GEP diluted in PBS were added to the wells $(1.127,2.254,4.508,6.762,9.016$, 11.270 and $13.524 \mathrm{mg} / \mathrm{ml}$ of GEP for C. albicans and 1.803 , 2.254, 2.705, 3.156, 3.606, 4.057 and $4.508 \mathrm{mg} / \mathrm{ml}$ of GEP for E. coli, S. aureus and P. aeruginosa); $100 \mu \mathrm{l}$ of PBS was added to the negative control wells and $100 \mu 1$ of $75 \%$ ethanol (analytical pure) was added to the positive control wells. The plates were cultured for $24 \mathrm{~h}$ at $37^{\circ} \mathrm{C}$ (bacterial strains) or $28^{\circ} \mathrm{C}$ (C. albicans), and $20 \mu 1$ of $0.2 \%$ triphenyltetrazolium chloride (Sigma-Aldrich; Merck KGaA) was added to the bacterial suspensions and $20 \mu 1 \mathrm{of} 5 \mathrm{mg} / \mathrm{ml}$ MTT was added to the fungal suspensions, as previously described $(21,22)$. The plates were incubated for a further $4 \mathrm{~h}$ in darkness. MIC was defined as the minimum concentration of GEP that completely inhibited cell viability, as shown by the absence of formazan crystal formation. After observation, formazan crystals were dissolved using DMSO and were measured at $490 \mathrm{~nm}$ for the three bacterial strains and $570 \mathrm{~nm}$ for C.albicans. The same results were obtained from analysis under a microscope.

Construction of growth curves. In total, $20 \mathrm{ml}$ of bacterial or fungal suspensions $\left(1 \times 10^{6} \mathrm{CFU} / \mathrm{ml}\right)$ was mixed with $20 \mathrm{ml}$ of 2X MIC GEP (1X MIC treated group) or PBS (Control group), and cultured at the aforementioned temperatures. The optical density at $600 \mathrm{~nm}$ was determined using $1 \mathrm{ml}$ of mixture using a Synergy HT Multi-detection microplate reader (Omega Bio-Tek, Inc.) at 0, 1, 2, 4, 6, 8 and $10 \mathrm{~h}$ for E. coli and P. aeruginosa, and $0,1,2,4,6,8,12,16$ and $20 \mathrm{~h}$ for C. albicans and S. aureus.

Scanning electron microscopy (SEM) analysis. The bacterial and fungal suspensions at a final density of $5 \times 10^{5} \mathrm{CFU} / \mathrm{ml}$ mixed with GEP (1X MIC treatment group) or an equal volume of PBS (Control group) were incubated for $16 \mathrm{~h}$ at $37^{\circ} \mathrm{C}$ (bacterial strains) or $28^{\circ} \mathrm{C}($ C. albicans). After centrifugation at $604 \mathrm{x}$ g at room temperature for $5 \mathrm{~min}$ and washing with PBS three times, the collected precipitates were fixed with $2.5 \%(\mathrm{v} / \mathrm{v})$ glutaraldehyde for $2 \mathrm{~h}$ at $4{ }^{\circ} \mathrm{C}$, dehydrated by an ascending series of ethanol washes (30-100\%), freeze-dried and gold-sputtered. Samples were observed by SEM using a Hitachi X650 (Hitachi, Ltd.).

Determination of optical density $(O D)$ at $260 \mathrm{~nm}$ to detect $D N A$ and RNA. The bacterial and fungal suspensions (final density, $5 \times 10^{5} \mathrm{CFU} / \mathrm{ml}$ ) mixed with GEP (1X MIC treatment group) or PBS (Control group) were incubated for 0 or $2 \mathrm{~h}$. At each time point, $1 \mathrm{ml}$ of mixture was removed, centrifuged at $9,660 \mathrm{x} \mathrm{g}$ at room temperature for $10 \mathrm{~min}$ and the resulting supernatant passed through a microporous filter $(0.22 \mu \mathrm{m}$; EMD Millipore). The optical density of the resulting supernatant was measured at $260 \mathrm{~nm}$ using a microplate reader (23).

Determination of the activities of extracellular enzymes. In the preliminary experiments to determine extracellular alkaline phosphatase (AKP) activity, samples were collected from the supernatants of each strain after 1, 2, 4, 8 and $10 \mathrm{~h} 1 \mathrm{X}$ MIC GEP or PBS Control treatment. AKP activity was detected using an AKP assay kit (cat. no. A059-1; Nanjing Jiancheng Bioengineering Institute). According to the preliminary results (Fig. S1), a $2 \mathrm{~h}$ incubation was selected for the subsequent experiments.

In the preliminary experiments, the extracellular $\beta$-galactosidase activity was detected in the cultured medium after 1,2,4,8 and $10 \mathrm{~h} 1 \mathrm{X}$ MIC GEP or PBS Control treatment. According the preliminary results (Fig. S2), a $4 \mathrm{~h}$ incubation 
was selected for the subsequent experiments. Samples $(100 \mu \mathrm{l})$ were added to $400 \mu 10.05 \mathrm{~mol} / \mathrm{l} \mathrm{O}$-nitrophenyl- $\beta$-D-galacto pyranoside (ONPG; Sigma-Aldrich; Merck KGaA) and the mixture was incubated in a water bath at $37^{\circ} \mathrm{C}$ for $40 \mathrm{~min}$. The resulting mixture was immediately combined with $500 \mu \mathrm{l}$ $0.5 \mathrm{~mol} / 1$ sodium bicarbonate and the optical density at $420 \mathrm{~nm}$ was measured using a microplate reader. The formula for the calculation of $\beta$-galactosidase activity is as follows $(24,25)$ : $\beta$-Galactosidase activity $(\mathrm{U} / \mathrm{ml})=\left(\mathrm{OD}_{420} \times \mathrm{A}\right) /(\mathrm{B} \times \mathrm{C} \times 0.0045)$ where A represents the volume of the system $(\mathrm{ml}), \mathrm{B}$ represents the incubation time ( $\mathrm{min}), \mathrm{C}$ represents the sample volume $(\mathrm{ml})$ and 0.0045 represents the molar extinction coefficient of ONPG (ml/nmol).

Determination of the activities of intracellular enzymes. After incubation for $10 \mathrm{~h}$, the treated bacteria and fungi were collected by centrifugation at $604 \mathrm{x} \mathrm{g}$ at room temperature for $5 \mathrm{~min}$ and washed with PBS. Intracellular proteins were extracted using a bacterial protein extraction kit (cat. no. BB-3123; Best Science) or yeast total protein extraction kit (cat. no. BB-3125; Best Bio Science). The concentration of the protein samples was determined using the BCA method.

The activities of intracellular malate dehydrogenase (MDH; cat. no. A021-2), succinate dehydrogenase (SDH; cat. no. A022), ATPase (cat. no. A095-1), $\mathrm{Na}^{+} / \mathrm{K}^{+}$-ATPase (cat. no. A070-2) and $\mathrm{Ca}^{2+}$-ATPase (cat. no. A070-4) were determined according to the instructions for the commercial kits (all from Nanjing Jiancheng Bioengineering Institute).

Statistical analysis. All data are presented as the mean \pm SD and represent six independent experiments; each experiment was performed in triplicate. Statistical significance was determined using two-tailed Student's t-tests using SPSS Statistics v24 (IBM Corp.) for Windows. P>0.05 was considered to indicate a statistically significant difference.

\section{Results}

Molar mass distribution of GEP. Mw/Mn is defined as the polydispersity index, representing the dispersion of the molecular weight of GEP. The smaller the polydispersity index value, the more uniform in molar mass the sample is. The Mw/Mn of GEP was determined to be 4.820 , which suggested that the molecular weight of GEP is moderately uniform (Table I).

MICs of GEP against the four microbial strains. GEP had the highest MIC value for C. albicans $(5.635 \mathrm{mg} / \mathrm{ml})$ and the lowest MIC value for $S$. aureus $(1.127 \mathrm{mg} / \mathrm{ml}$ ) (Table II). The MIC values of GEP against $E$. coli and $P$. aeruginosa were 1.803 and $1.352 \mathrm{mg} / \mathrm{ml}$, respectively. These data suggested that gram-negative bacteria ( $E$. coli, $P$. aeruginosa) and gram-positive bacteria ( $S$. aureus) are more sensitive to GEP than fungi (C. albicans).

Effects of GEP on the growth of the four microbial strains. Growth curves were constructed from 0 to 10 or $20 \mathrm{~h}$ for the different strains to investigate the effects of GEP at $1 \mathrm{X}$ MIC on antimicrobial properties over time (26). Compared with the respective PBS-treated Control groups, the number of cells was significantly lower following treatment with GEP
Table I. The molar mass distribution of GEP.

\begin{tabular}{ll}
\hline Parameter & GEP \\
\hline $\mathrm{Mw} / \mathrm{Mn}$ & 4.820 \\
$\mathrm{Mn}(\mathrm{g} / \mathrm{mol})$ & $1.102 \times 10^{4}$ \\
$\mathrm{Mw}(\mathrm{g} / \mathrm{mol})$ & $5.310 \times 10^{4}$ \\
$\mathrm{Mz}(\mathrm{g} / \mathrm{mol})$ & $3.142 \times 10^{5}$
\end{tabular}

GEP, polypeptide-enriched Gastrodia elata extracts; Mn, number average molar mass; Mw, weight-average molar mass; Mz, z-average molar mass.

Table II. MICs of polypeptide-enriched Gastrodia elata extracts against four microbial strains.

\begin{tabular}{lc}
\hline Microbial strain & MIC (mg/ml) \\
\hline Candida albicans & 5.635 \\
Escherichia coli & 1.803 \\
Staphylococcus aureus & 1.127 \\
Pseudomonas aeruginosa & 1.352 \\
\hline
\end{tabular}

MIC, minimum inhibitory concentration.

(1X MIC), which suggested that GEP inhibits the growth of C. albicans, E. coli, S. aureus and P. aeruginosa (Fig. 1); GEP almost completely inhibited the growth of E.coli (Fig. 1B) and S. aureus (Fig. 1C).

Effects of GEP on cell wall integrity. To investigate the morphology and the integrity of the cell wall of the four microbial strains, SEM was performed and the activity of AKP was determined. PBS-treated $C$. albicans and S. aureus cells had a smooth and plump sphere shape, whereas following $16 \mathrm{~h}$ of GEP treatment vesication or the formation of irregular protruding structures were observed on the cell surface (Fig. 2). For E. coli and P. aeruginosa, compared with the control group, cell-surface damage, such as uneven spots and curves, was apparent in the GEP-treated groups (Fig. 2). Some visible cell debris was observed in the GEP-treated E. coli and S. aureus (Fig. 2).

AKP, a phosphatase found between the cell wall and cell membrane, serves as an index for cell wall permeability (27). Compared with the Control group, GEP (1X MIC) treatment for $2 \mathrm{~h}$ caused a 43.9-fold $(\mathrm{P}<0.001), 10.0$-fold $(\mathrm{P}<0.001)$, 4.4-fold $(\mathrm{P}<0.001)$ and 8.8 -fold $(\mathrm{P}<0.001)$ increase in the extracellular AKP activity for C. albicans, E. coli, $S$. aureus and $P$. aeruginosa, respectively (Fig. 3), which suggested that GEP treatment resulted in damage and disruption to the cell wall.

Effects of GEP on cell membrane permeability. $\beta$-Galactosidase is an intracellular enzyme that leaks from cells following damage to the cell membrane; therefore, $\beta$-galactosidase can be used as an indicator of cell membrane 

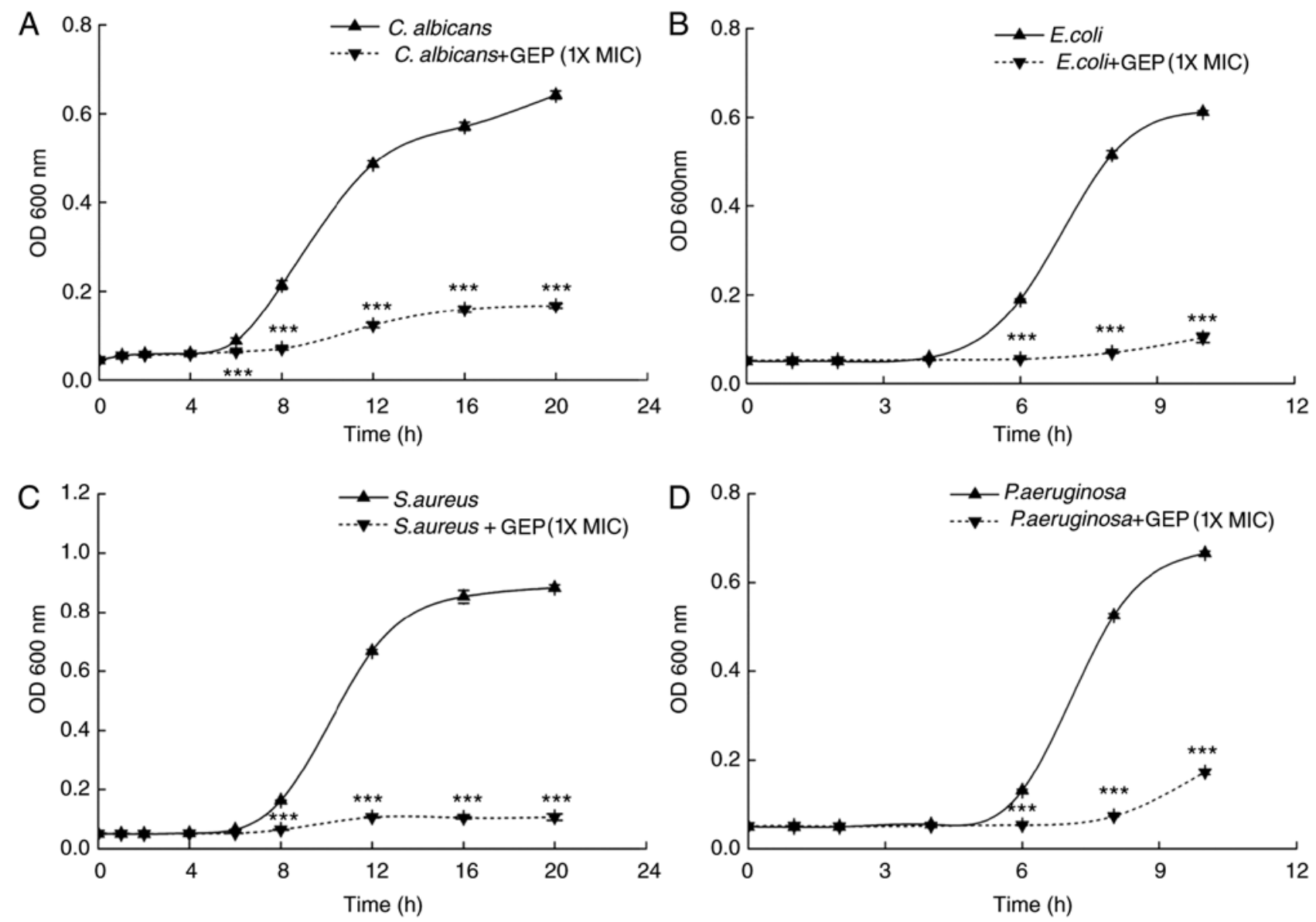

Figure 1. GEP (1X MIC) inhibits the growth rate of microbial strains. GEP treatment at $1 \mathrm{X}$ MIC inhibited the growth rate of (A) Candida albicans, (B) Escherichia coli, (C) Staphylococcus aureus and (D) Pseudomonas aeruginosa. Data are presented as the mean $\pm \mathrm{SD} ; \mathrm{n}=6$; ${ }^{* * *} \mathrm{P}<0.001 \mathrm{vs.}$ respective Control. GEP, polypeptide-enriched Gastrodia elata extracts; MIC, minimum inhibitory concentration; OD, optical density.
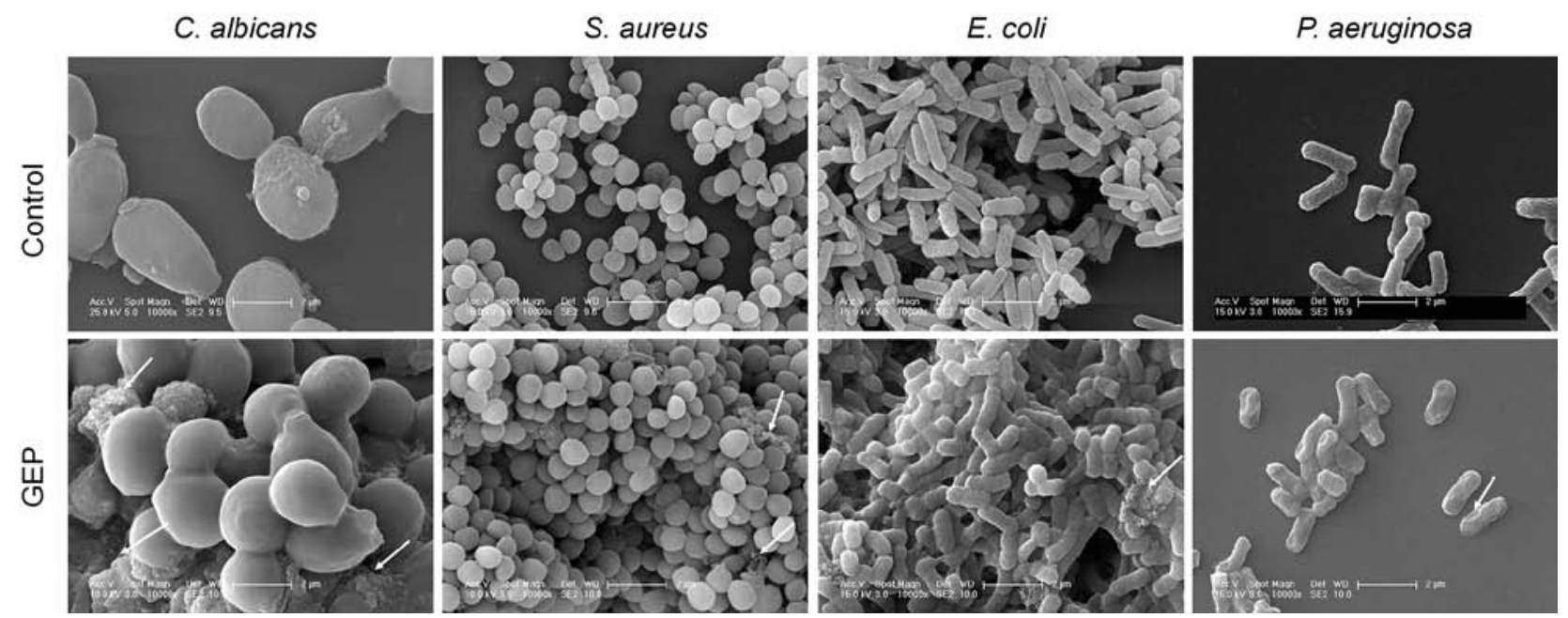

Figure 2. SEM images of the microbial strains following treatment with GEP. SEM images demonstrating the effects of GEP (1X MIC) on the cell morphology of Candida albicans, Escherichia coli, Staphylococcus aureus and Pseudomonas aeruginosa; magnification, x10,000. GEP, polypeptide-enriched Gastrodia elata extracts; MIC, minimum inhibitory concentration; SEM, scanning electron microscopy.

integrity (25). Compared with the Control group, treatment with GEP (1X MIC) for $4 \mathrm{~h}$ resulted in a $28.3(\mathrm{P}<0.001), 7.6$ $(\mathrm{P}<0.001), 8.1(\mathrm{P}<0.01)$ and $7.1 \%(\mathrm{P}<0.01)$ increase in extracellular $\beta$-galactosidase activity in the samples of $C$. albicans, E. coli, S. aureus and P. aeruginosa, respectively (Fig. 4A).
Ion pumps, such as the $\mathrm{Na}^{+} / \mathrm{K}^{+}$-ATPase and the $\mathrm{Ca}^{2+}$-ATPase, are important membrane proteins that regulate cell membrane permeability (28). Compared with the Control group, treatment with GEP (1X MIC) resulted in a decrease in the activities of $\mathrm{Na}^{+} / \mathrm{K}^{+}$-ATPase (Fig. 4B) 


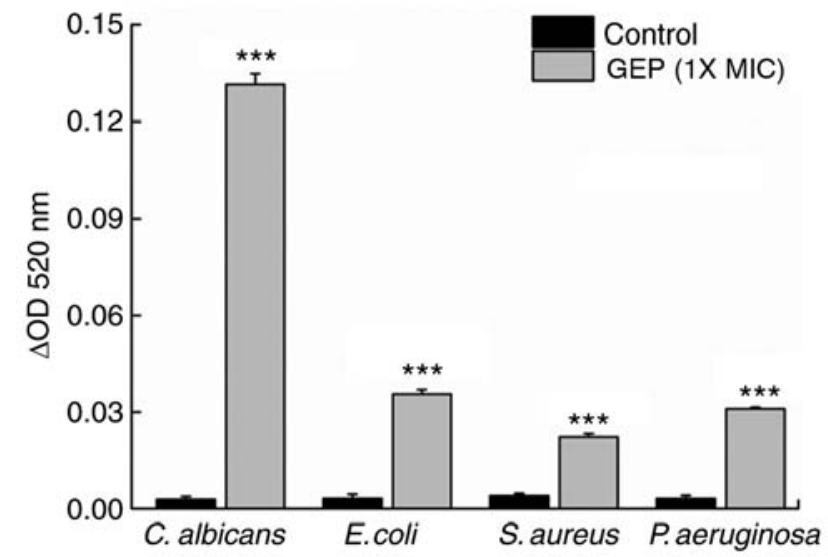

Figure 3. Effects of GEP on the extracellular activity of AKP. The extracellular activity of AKP in Candida albicans, Escherichia coli, Staphylococcus aureus and Pseudomonas aeruginosa was determined following a $2 \mathrm{~h}$ incubation with GEP (1X MIC). Data are presented as the mean $\pm \mathrm{SD} ; \mathrm{n}=6$; ${ }^{* * *} \mathrm{P}<0.001$ vs. respective Control. $\triangle \mathrm{OD}$, change in optical density; GEP, polypeptide-enriched Gastrodia elata extracts; MIC, minimum inhibitory concentration.

and $\mathrm{Ca}^{2+}$-ATPase (Fig. 4C) of $88.3(\mathrm{P}<0.001)$ and $73.5 \%$ $(\mathrm{P}<0.001)$, respectively, for $C$. albicans; $16.9(\mathrm{P}<0.001)$ and $65.5 \%(\mathrm{P}<0.001)$, respectively, for E. coli; $64.7(\mathrm{P}<0.001)$ and $36.9 \%(\mathrm{P}<0.001)$, respectively, for $S$. aureus; and 51.3 $(\mathrm{P}<0.001)$ and $22.7 \%(\mathrm{P}<0.001)$ for $P$. aeruginosa. These findings suggested that GEP damaged the cell membranes of these microbial strains.

Effects of GEP on the leakage of genetic material. A high $\mathrm{OD}_{260}$ may be detected following the leakage of nucleotides (25). Compared with the Control group, GEP (1X MIC) treatment caused a $590 \%(\mathrm{P}<0.001)$ increase in the $\mathrm{OD}_{260}$ between 0 and $2 \mathrm{~h}$ in S.aureus and a $530 \%(\mathrm{P}<0.001)$ increase for P. aeruginosa (Fig. 5); a $100(\mathrm{P}<0.001)$ and $80 \%(\mathrm{P}<0.01)$ increase in the OD was observed for $C$. albicans and $E$. coli, respectively. These results indicated that GEP may cause leakage of genetic material from these microorganisms.

Effects of GEP on intracellular enzyme activity. SDH, MDH and ATPases serve important roles in microbial energy metabolism. ATPases hydrolyze ATP and provide energy to drive other chemical reaction in the cell (29). Compared with the Control group, GEP (1X MIC) treatment reduced the activity of ATPases by $100.0(\mathrm{P}<0.001), 39.4(\mathrm{P}<0.01), 93.0(\mathrm{P}<0.001)$ and $87.1 \%(\mathrm{P}<0.001)$ in $C$. albicans, E. coli, S. aureus and $P$. aeruginosa, respectively (Fig. 6A).

$\mathrm{MDH}$ affects biosynthesis through its coenzyme $\mathrm{NADP}^{+}$ (29); SDH is an important marker of the health of microbial energy metabolism. Compared with the Control group, GEP (1X MIC) treatment reduced the activity of MDH by $78.4(\mathrm{P}<0.001), 76.6(\mathrm{P}<0.001), 89.4(\mathrm{P}<0.001)$ and $50.2 \%$ $(\mathrm{P}<0.01)$ in $C$. albicans, E. coli, $S$. aureus and P. aeruginosa, respectively (Fig. 6B). GEP treatment suppressed the activity of SDH by $21.1(\mathrm{P}<0.05), 48.6(\mathrm{P}<0.001), 25.1 \quad(\mathrm{P}<0.001)$ and $70.7 \%(\mathrm{P}<0.001)$ in C. albicans, E. coli, S. aureus and $P$. aeruginosa, respectively (Fig. 6C). These data suggested that GEP treatment disturbed energy metabolism in these microorganisms.
A
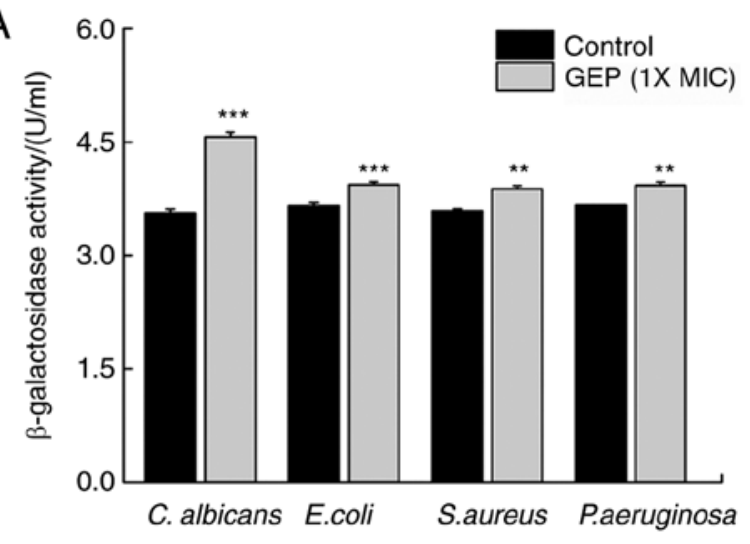

B
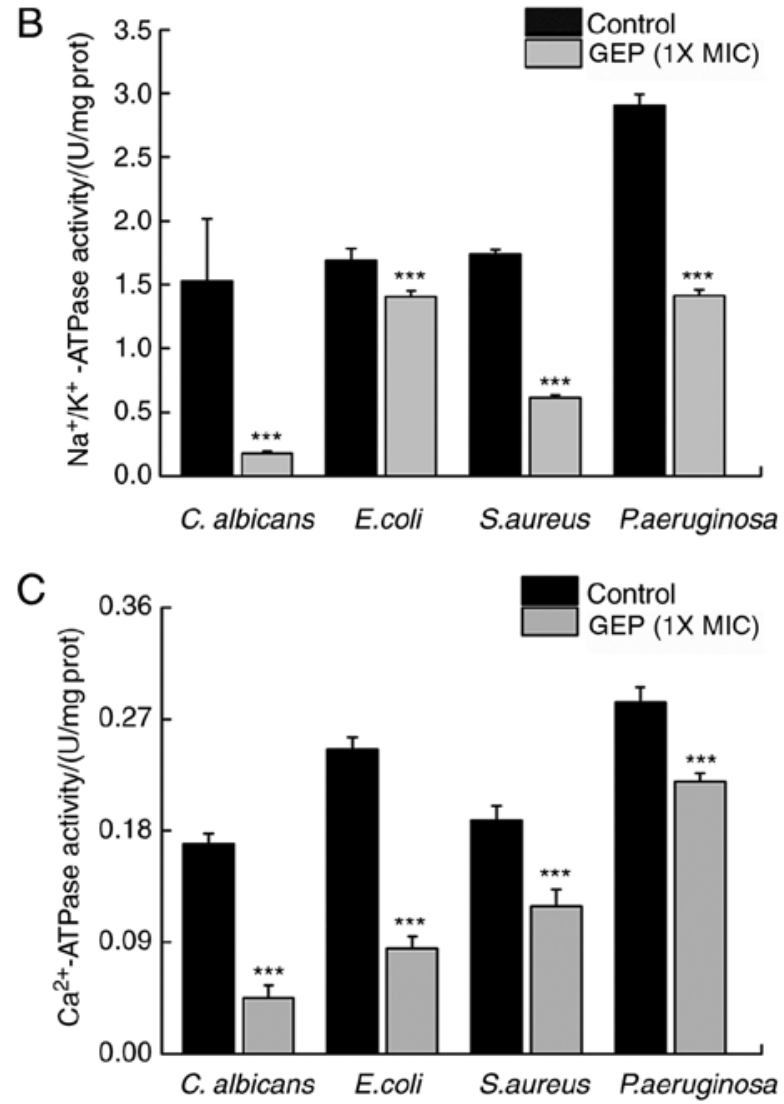

Figure 4. Effects of GEP on cell membrane permeability. Effects of GEP treatment at $1 \mathrm{X}$ MIC on the activities of (A) extracellular $\beta$-galactosidase, (B) the $\mathrm{Na}^{+} / \mathrm{K}^{+}$-ATPase and (C) the $\mathrm{Ca}^{2+}$-ATPase in Candida albicans, Escherichia coli, Staphylococcus aureus and Pseudomonas aeruginosa following a $4 \mathrm{~h}$ incubation with GEP (1X MIC). Data are presented as the mean $\pm \mathrm{SD} ; \mathrm{n}=6 ;{ }^{* *} \mathrm{P}<0.01$ and ${ }^{* * *} \mathrm{P}<0.001$ vs. respective Control. GEP, polypeptide-enriched Gastrodia elata extracts; MIC, minimum inhibitory concentration; prot, protein.

\section{Discussion}

The antimicrobial activity of GEP against fungi and gram-positive bacteria has been reported previously $(19,20)$. Our previous study demonstrated the antimicrobial activities of GEP using the agar diffusion method (20) and are now investigating the therapeutic efficacy of GEP against vulvovaginal candidiasis in mice (30). In the present study, it was demonstrated that the effects of GEP may derive from the damage caused to cell walls and membranes, triggering the leakage of genetic material and disrupting cellular metabolism. 


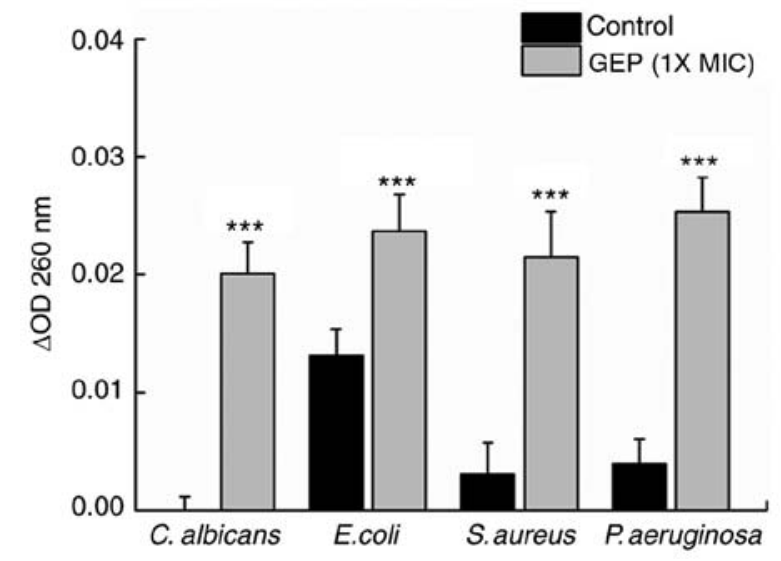

Figure 5. Effects of GEP on the leakage of genetic material. GEP treatment at $1 \mathrm{X}$ MIC increases the leakage of genetic material from Candida albicans, Escherichia coli, Staphylococcus aureus and Pseudomonas aeruginosa. Data are presented as the mean $\pm \mathrm{SD} ; \mathrm{n}=6 ;{ }^{* * * *} \mathrm{P}<0.001$ vs. respective Control. $\triangle \mathrm{OD}$, change in optical density; GEP, polypeptide-enriched Gastrodia elata extracts; MIC, minimum inhibitory concentration.

The SEM results demonstrated that GEP damaged cell walls and membranes, leading to changes in cell morphology and cell death These changes may result in the loss of intracellular material (31). Various antibacterial agents act primarily on the cell membrane (32), which is a selectively permeable barrier that enables the normal growth of bacteria (23). Leakage of intracellular substances serves as an indicator of membrane integrity. AKP is present between the cell wall and the cell membrane $(33,34)$. Damage to the cell wall increases cell permeability, leading to the leakage of AKP (27). The enhanced extracellular AKP levels within $2 \mathrm{~h}$ of treatment with GEP are consistent with the SEM results, and further suggested that GEP damaged cell walls and membranes.

$\beta$-Galactosidase is an important microbial enzyme that hydrolyzes lactose into galactose and glucose to produce energy, and provide a source of carbon (35). In the present study, it was demonstrated that GEP may regulate energy metabolism in bacteria and fungi. In addition to enhancing the extracellular activities of $\beta$-galactosidase, GEP directly suppressed the intracellular activity levels of SDH and $\mathrm{MDH}$ in the four microbial strains. The tricarboxylic acid (TCA) cycle is the metabolic pathway linking the three major classes of nutrients (sugars, lipids and amino acids) and the main energy production mode of the four microbial strains examined. MDH catalyzes the reversible conversion of malic acid and oxaloacetic acid in the last step of the TCA cycle, influencing ATP production (36,37). SDH provides electrons for the respiratory chain. Decreased SDH activity inhibits mitochondrial electron transport and oxidative respiration, resulting in ATP consumption, thus hindering the TCA cycle and energy metabolism (37,38).

ATPases hydrolyzes ATP to release energy (23). As previously reported, the inhibition of the ATPase activity of $\mathrm{Ca}^{2+}$-ATPase and $\mathrm{Na}^{+} / \mathrm{K}^{+}$-ATPase leads to an overload of intracellular $\mathrm{Ca}^{2+}$ and $\mathrm{Na}^{+}$, the inhibition of energy metabolism, a reduction in ATP production and an imbalance of osmotic pressure, which causes cell swelling and apoptosis (38). The data from the present study suggested that these changes in energy metabolism may be one of the reasons for the antimicrobial efficacy of GEP.
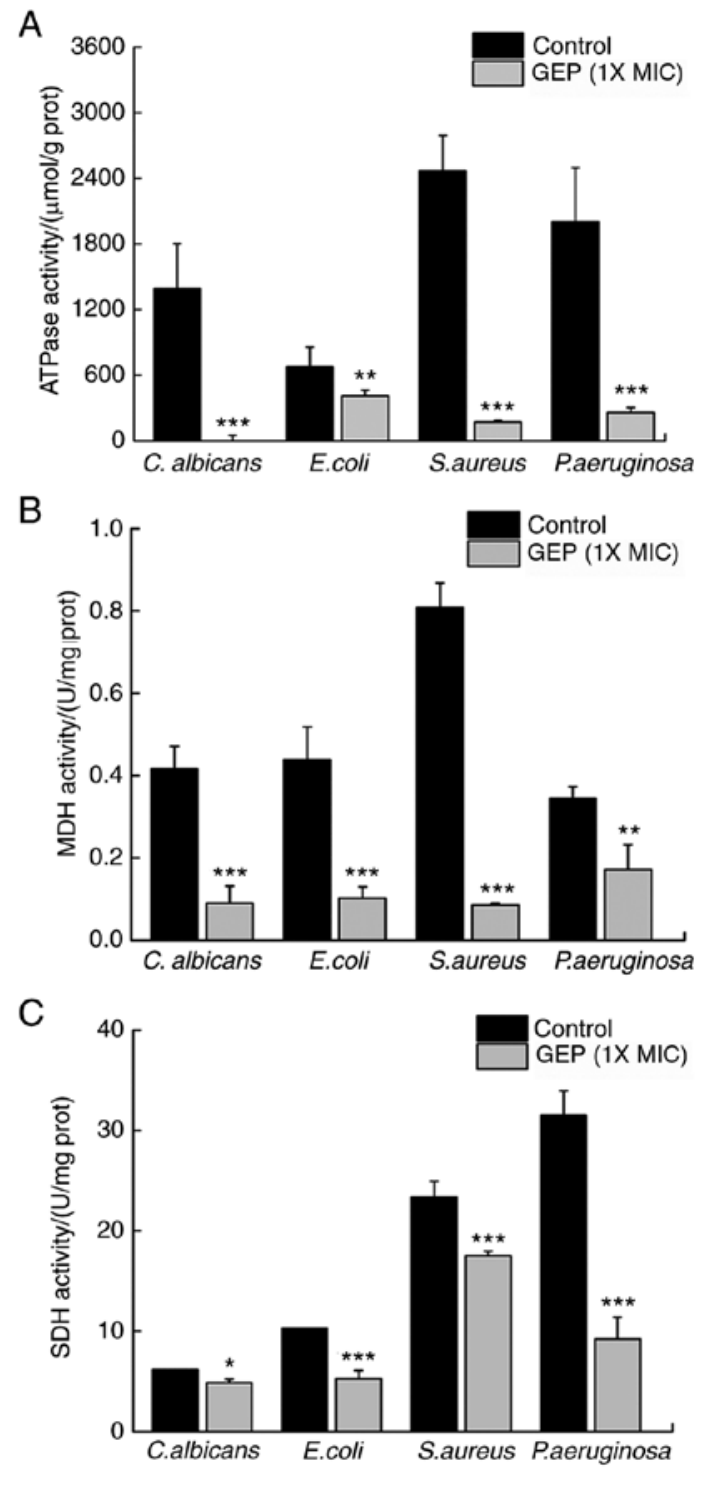

Figure 6. Effects of GEP on the activities of tricarboxylic acid cycle-related enzymes. GEP treatment at $1 \mathrm{X}$ MIC reduced the activity levels of (A) ATPases, (B) MDH and (C) SDH in Candida albicans, Escherichia coli, Staphylococcus aureus and Pseudomonas aeruginosa. Data are presented as the mean $\pm \mathrm{SD} ; \mathrm{n}=6 ;{ }^{*} \mathrm{P}<0.05,{ }^{* *} \mathrm{P}<0.01$ and ${ }^{* * *} \mathrm{P}<0.001$ vs. respective Control. GEP, polypeptide-enriched Gastrodia elata extracts; MDH, malate dehydrogenase; MIC, minimum inhibitory concentration; prot, protein; SDH, succinate dehydrogenase.

In the present study, the possible mechanisms underlying the antimicrobial activities of GEP were investigated, and the results indicated that GEP may disrupt energy metabolism, especially the TCA cycle, and may also be able to damage microbial cell walls and membranes, causing the leakage of genetic material.

\section{Acknowledgements}

Not applicable.

\section{Funding}

The present study was funded by The Special Projects of the Cooperation between Jilin University and Jilin Province (grant no. SXGJXX2017-1) and The Industrial Technology 
Research and Development Projects from Development and Reform Commission of Jilin Province (grant no. 2019C050-8).

\section{Availability of data and materials}

All data generated and analyzed during this study are included in this published article.

\section{Authors' contributions}

DW and HB designed the experiments. FK, XC, SZ, RW, XZ and YM performed the experiments. FK, XC, SZ and RW contributed to data analysis and proofreading. DW, FK and $\mathrm{XC}$ wrote the paper. DW and HB revised the paper.

\section{Ethics approval and consent to participate}

Not applicable.

\section{Patient consent for publication}

Not applicable.

\section{Competing interests}

The authors declare that they have no competing interests.

\section{References}

1. Wilson D: Candida albicans. Trends Microbiol 27: 188-189, 2019.

2. Wang Y, Bojer MS, George SE, Wang Z, Jensen PR, Wolz C and Ingmer H: Inactivation of TCA cycle enhances Staphylococcus aureus persister cell formation in stationary phase. Sci Rep 8 $10849,2018$.

3. Babii C, Bahrin LG, Neagu AN, Gostin I, Mihasan M, Birsa LM and Stefan M: Antibacterial activity and proposed action mechanism of a new class of synthetic tricyclic flavonoids. J Appl Microbiol 120: 630-637, 2016.

4. Hanna H, Benjamin R, Chatzinikolaou I, Alakech B, Richardson D, Mansfield P,Dvorak T, Munsell MF, Darouiche R, Kantarjian H and Raad I: Long-term silicone central venous catheters impregnated with minocycline and rifampin decrease rates of catheter-related bloodstream infection in cancer patients: A prospective randomized clinical trial. J Clin Oncol 22: 3163-3171, 2004.

5. Sunada K, Watanabe T and Hashimoto K: Studies on photokilling of bacteria on $\mathrm{TiO}_{2}$ thin film. J Photochem Photobiol A Chem 156: 227-233, 2003.

6. Klibanov AM: Permanently microbicidal materials coatings. J Mater Chem 17, 2007.

7. Oger PC, Piesse C, Ladram A and Humblot V: Engineering of antimicrobial surfaces by using temporin analogs to tune the biocidal/antiadhesive effect. Molecules 24: 814, 2019.

8. Cardon S, Sachon E, Carlier L, Drujon T, Walrant A, Alemán-Navarro E, Martínez-Osorio V, Guianvarc'h D, Sagan S, Fleury Y, et al: Peptidoglycan potentiates the membrane disrupting effect of the carboxyamidated form of DMS-DA6, a Gram-positive selective antimicrobial peptide isolated from Pachymedusa dacnicolor skin. PLoS One 13: e0205727, 2018.

9. Burt S: Essential oils: Their antibacterial properties and potential applications in foods-a review. Int J Food Microbiol 94: 223-253, 2004.

10. Gibbons S: Anti-staphylococcal plant natural products. Nat Prod Rep 21: 263-277, 2004.

11. Khan MI, Ahhmed A, Shin JH, Baek JS, Kim MY and Kim JD Green tea seed isolated saponins exerts antibacterial effects against various strains of gram positive and gram negative bacteria, a comprehensive study in vitro and in vivo. Evid Based Complement Alternat Med 2018: 3486106, 2018
12. Liu M, Yang K, Wang J, Zhang J, Qi Y, Wei X and Fan M: Young astringent persimmon tannin inhibits methicillin-resistant Staphylococcus aureus isolated from pork. LWT 100: 48-55, 2019.

13. Fernebro J: Fighting bacterial infections-future treatment options. Drug Resist Updat 14: 125-139, 2011.

14. Matias M, Silvestre S, Falcão A and Alves G: Gastrodia elata and epilepsy: Rationale and therapeutic potential. Phytomedicine 23: 1511-1526, 2016.

15. Wu J, Wu B, Tang C and Zhao J: Analytical techniques and pharmacokinetics of gastrodia elata blume and its constituents. Molecules 22: pii: E1137, 2017.

16. Ojemann LM, Nelson WL, Shin DS, Rowe AO and Buchanan RA: Tian ma, an ancient Chinese herb, offers new options for the treatment of epilepsy and other conditions. Epilepsy Behav 8: 376-383, 2006.

17. Wang H, Zhang R, Qiao Y, Xue F, Nie H, Zhang Z, Wang Y, Peng $Z$ and Tan Q: Gastrodin ameliorates depression-like behaviors and up-regulates proliferation of hippocampal-derived neural stem cells in rats: Involvement of its anti-inflammatory action. Behav Brain Res 266: 153-160, 2014.

18. Hwang SM, Lee YJ, Kang DG and Lee HS: Anti-inflammatory effect of Gastrodia elata rhizome in human umbilical vein endothelial cells. Am J Chin Med 37: 395-406, 2009.

19. Chen C, Li X, Li J, Xu Y, Jing X, Wu S, Liu X and Zhang X: Purification and characterization of an antimicrobial protein from Gastrodia elata Blume tubers. Trop J Pharm Res 17: No. 9, 2018.

20. Wang X, Lu J, Chen Y, Zhao Y, Tong P, Teng L and Wang D: Optimization of the extraction of gastrodia elata protein and its antibacterial. J Chin Inst Food Sci Technol 18: 176-128, 2018.

21. Kifer D, Mužinić V and Klarić MŠ: Antimicrobial potency of single and combined mupirocin and monoterpenes, thymol, menthol and 1,8-cineole against Staphylococcus aureus planktonic and biofilm growth. J Antibiot (Tokyo) 69: 689-696, 2016.

22. Silva JP, Peres AR, Paixão TP, Silva AS, Baetas AC, Barbosa WL, Monteiro MC and Andrade MA: Antifungal activity of hydroalcoholic extract of chrysobalanus icaco against oral clinical isolates of candida species. Pharmacognosy Res 9: 96-100, 2017.

23. Sun XH, Zhou TT, Wei CH, Lan WQ, Zhao Y, Pan YJ and Wu Vivian CH: Antibacterial effect and mechanism of anthocyanin rich Chinese wild blueberry extract on various foodborne pathogens. Food Control 94: 155-161, 2018.

24. Wang J, Ma M, Yang J, Chen L, Yu P, Wang J, Gong D, Deng S, Wen $X$ and Zeng Z: In vitro antibacterial activity and mechanism of monocaprylin against escherichia coli and staphylococcus aureus. J Food Prot 81: 1988-1996, 2018.

25. Shen S, Zhang T, Yuan Y, Lin S, Xu J and Ye H: Effects of cinnamaldehyde on Escherichia coli and Staphylococcus aureus membrane. Food Control 47: 196-202, 2015.

26. Su R, Li T, Fan D, Huang J, Zhao J, Yan B, Zhou W, Zhang W and Zhang $\mathrm{H}$ : The inhibition mechanism of $\epsilon$-polylysine against Bacillus cereus emerging in surimi gel during refrigerated storage. J Sci Food Agric 99: 2922-2930, 2019.

27. He N, Wang P, Wang P, Ma C and Kang W: Antibacterial mechanism of chelerythrine isolated from root of Toddalia asiatica (Linn) Lam. BMC Complement Altern Med 18: 261, 2018.

28. Li X, He C, Song L, Li T, Cui S, Zhang L and Jia Y: Antimicrobial activity and mechanism of Larch bark procyanidins against Staphylococcus aureus. Acta Biochim Biophys Sin (Shanghai) 49: 1058-1066, 2017.

29. Li T, Yang SR, Chen M, Song LY and He CF: Antibacterial mechanism of ginger mix-fried magnolia bark extract against escherichia coli and staphylococcus aureus. Modern Food Sci Technol 32: 84-92, 2016.

30. Cai X, Kong F, Wang R, Zhai S, Guan X, Zhang G and Wang D: Candida albicans vaginitis in a murine model is reduced by polypeptide-enriched Gastrodia elata extracts. Future Microbiol 14: 839-846, 2019.

31. Bajpai VK, Al-Reza SM, Choi UK, Lee JH and Kang SC: Chemical composition, antibacterial and antioxidant activities of leaf essential oil and extracts of Metasequioa glyptostroboides Miki ex Hu. Food Chem Toxicol 47: 1876-1883, 2009.

32. Eom SH, Lee DS, Jung YJ, Park JH, Choi JI, Yim MJ, Jeon JM, Kim HW, Son KT, Je JY, et al: The mechanism of antibacterial activity of phlorofucofuroeckol-A against methicillin-resistant Staphylococcus aureus. Appl Microbiol Biotechnol 98: 9795-9804, 2014. 
33. Cui H, Zhang C, Li C and Lin L: Antimicrobial mechanism of clove oil on Listeria monocytogenes. Food Control 94: 140-146, 2018.

34. Guo L, Zhang F, Wang X, Chen H, Wang Q, Guo J, Cao X and Wang L: Antibacterial activity and action mechanism of questin from marine Aspergillus flavipes $\mathrm{HN} 4-13$ against aquatic pathogen Vibrio harveyi. 3 Biotech 9: 14, 2019.

35. Watson AL and Chiu NHL: Fluorometric cell-based assay for $\beta$-galactosidase activity in probiotic gram-positive bacterial cells-Lactobacillus helveticus. J Microbiol Methods 128: 58-60, 2016.
36. Bhatt DK and Bano M: Modulation of tricarboxylic acid cycle dehydrogenases during hepatocarcinogenesis induced by hexachlorocyclohexane in mice. Exp Toxicol Pathol 61: 325-332, 2009.

37. Li Y, Shao X, Xu J, Wei Y, Xu F and Wang H: Tea tree oil exhibits antifungal activity against Botrytis cinerea by affecting mitochondria. Food Chem 234: 62-67, 2017.

38. Fu Y, Jia FB, Wang J, Song M, Liu SM, Li YF, Liu SZ and $\mathrm{Bu}$ QW: Effects of sub-chronic aluminum chloride exposure on rat ovaries. Life Sci 100: 61-66, 2014. 